\title{
Fikstür ve Aparatların Yazılım Aracılığıyla Otomasyonu: Eskişehir İlinde Talaşıı İmalat Yapan Bir Firmada Uygulaması
}

\author{
Hilmi Cenk BAYRAKÇI ${ }^{1}$, Muhammed DUMAN²
}

1'Isparta Uygulamalı Bilimler Üniversitesi, Teknoloji Fakültesi, Mekatronik Mühendisliği Bölümü, Isparta 2Isparta Uygulamalı Bilimler Üniversitesi, Lisansüstü Eğitim Enstitüsü, Mekatronik Mühendisliği Bölümü, Isparta

(Alınış / Received: 14.07.2020, Kabul / Accepted: 11.12.2020)

\section{Anahtar Kelimeler}

Talaşlı imalat, Otomasyon, Fikstür ve Yardımcı Ekipmanlar, Kurumsal Kaynak Planlama, ERP
Özet: Seri üretim yapan talaşlı imalat fabrikalarında zamanı etkili ve verimli kullanmak çok önemli bir yere sahiptir. Üretimi yapılan parçaların imalinden lojistiğine kadar olan süreçteki verimsizliklerin ortadan kaldırılması ile zaman etkili ve israf edilmeden kullanılmış olacaktır. Talaşlı imalat esnasında kullanılan ekipmanların doğru yerde doğru şekilde konumlanmış olması; bunları kullanacak personelin konumlu yerlerinden doğru șekilde alıp işini tamamladığında doğru şekilde bırakması, bir sonraki kullanımda zaman kaybı yaşanmaması adına çok önemlidir. Bu çalışmada, Eskişehir ilinde talaşlı imalat alanında hizmet veren bir firmada imalat esnasında kullanılan fikstür ve yardımcı ekipmanların takibinin bir otomasyon sistemi aracılığıyla kontrolü ele alınmıştır. Kullanılan bu yazılım sistemiyle elde edilen verim artışı ve hesaplanacak, ekipmanların izlenebilirliği sağlanacak ve firma genelinde kare kodlar aracılığıyla yapılacak uygulamalara zemin hazırlanacaktır.

\section{Automation of Fixtures and Apparatuses through Software: Implementation in a Manufacturing Company in Eskisehir}

Keywords

Machining,

Automation,

Fixtures and Auxiliary

equipment,, Enterprise

resource planning
Abstract: Using time effectively and efficiently is very important in machining plants. In case the inefficiencies in the process from the manufacturing unit to the logistics unit are eliminated, the time will be used effectively and without waste. Locating used equipment during machining process to the right places is very important for the personnel who will use next time. In this case staff will not waste time. If auxiliary equipment are positioned differently its locations, it causes delays in the workplace and risks in terms of occupational health and safety.

In our study, the control of the fixtures and auxiliary equipment used during manufacturing in a company working in the field of machining industry in Eskișehir will be discussed through an automation system. With this mentioned software system to be used, the increase in efficiency will be calculated, the traceability of the equipment will be provided and it will form the basis for the applications to be made through the QR codes within the company.

\section{Giriş}

Küresel dünya üzerinde sanayileşme ve ülkelerin imalat yarışları teknolojinin yeni imkânları doğrultusunda her geçen gün ivme kazanmaktadır. Global alanda rol oynayan firmalar imalat hızlarını artırabilmek ve pazar alanlarında karar verici konumda kalabilmek için teknolojik gelişimlere adapte olmak zorundadirlar.

Yüzlerce yıl önce su ve buhar gücünün imalatta kullanılması ile bașlayan endüstri devrimleri 
günümüze kadar çeşitli merhalelerden geçerek kendini sürekli yenilemiştir. Bu gelişim 21. yüzyılda özellikle internet bağlantısının imalat sektöründe kullanılmaya başlaması ile birlikte zirve noktasına ulaşmış ve 4. Sanayi Devriminin temellerinin atılmasına zemin hazırlamıştır.

Sahadaki verileri girdi olarak alan, anlamlı verileri sahaya çıktı olarak gönderen ve bünyesindeki veri tabanına istenildiği zaman ulaşılabilen yapılara akıllı sistemler denilir. Akıllı fabrikalar, akıllı sistemlerle üretim temeline dayanan son derece sistematik ve işlemlerin birbiriyle bağlantılı olduğu tesislerdir [1]. Geleceğin fabrikaları olarak ifade edilen ve henüz yeni bir tanım olduğu düşünülen Akıllı Fabrikalar kavramı Dördüncü Sanayi Devrimi'nin önemli sonuçlarından bir tanesidir.

Endüstri 4.0 uygulamalarının gelişmesi ile birlikte talaşlı imalat sektöründe de internet tabanlı otomasyon sistemleri vasitasıyla üretim süreçleri takip edilmeye başlanmış ve bu üretim süreçlerinde zaman tasarrufları gözlenmeye başlanmıştır. Zaman yönetiminin yapılması ve zamanın doğru planlanması ciddi önem arz eden sektörde; zaman planlamasında yapılacak yanlışlıklar firmalar içerisinde özelden genele doğru aksamalara sebep olacak, firmaların görünümünü olumsuz olarak etkileyecek ve bu olumsuzluklar müşteri potansiyelini kaybetmeye kadar gidebilecektir. Bunun bilincinde olan sektör firmaları bünyesindeki personellerini sürekli iyileştirme ve zaman tasarrufu bilinci oluşturmakta, Endüstri 4.0 uygulamalarını desteklemekte, bu sayede sürdürülebilir ilerlemeler ve tasarruflar sağlanmaktadır.

Birçok sektör Endüstri 4.0 uygulamalarına kısa sürede adapte olmuştur. Bu devrimin uygulama alanlarına birkaç örnek verecek olursak ilk olarak akla lojistik sektörü gelmektedir. Önceden sayımı ve kontrolü son derece karmaşık olan raflar ve depolama alanları artık RFID teknolojisi ya da QR kodlar ile anlık olarak takip edilebilmektedir. Ulaşım sektöründe ise sürücüsüz metrolar ve tramvaylar göze çarpmaktadır. İleri dönemlerde ise akıllı telefonlar aracılığıly sürücüsüz taksileri bulunduğumuz yere çağırabileceğimiz altyapılar şimdiden kurulmaya başlandı. Bir diğer uygulama örneği de montaj imalatı yapan fabrikalardır. Bu tür fabrikalarda operatörler sanal gerçeklik gözlükleri takarak montajı yapılacak parçaların nereye ve nasıl şekilde yerleştirileceği gösterilmektedir. Ĕger operatör montajı yapılacak parçayı yanlış şekilde yaparsa sanal gerçeklik gözlüğü uyarı vermektedir. Örneği verilen uygulamaların yanı sıra imalat sektöründe bilginin farklı kullanıcılardan toplanması, derlenmesi ve ihtiyaç duyulduğu bir zaman diliminde kolaylıkla bulunabilmesi önem arz etmektedir. Bu durum Endüstri 4.0 uygulamalarına bir yenisini daha katmıştır. Kurumsal Kaynak Planlaması olarak bilinen ve "Enterprise Resource Planning" ifadesinin baş harflerinden oluşan ERP sistemleri 21. yüzyılda firmaların en sık tercih ettiği uygulamalar arasına girmiştir. ERP sistemleri üzerine birçok tanımlama yapılmıştır. ERP' nin en temel özelliğini vurgulayan bir tanıma göre işletme birimlerinin birbirleri ile iletişim ve bilgi paylaşımı temeline dayanan ERP sistemleri işletmelerin finans, üretim, satın alma, satış, lojistik, insan kaynakları vb. is süreçlerinin entegre edilerek tek çatı altında toplanmasını sağlar [2]. ERP sistemi, işletme fonksiyonlarının bütünleştirilmesi yolu ile işletmenin farklı birimleri arası bilgi akışının kolaylaşmasını sağlayan organizasyonel bilgi sistemleridir [3]. Başka bir tanımda ise ERP sistemleri, işletmelerin bütün fonksiyonlarının ve birimlerinin süreçlerini ortak veri tabanında toplayıp, bu veri tabanı üzerinde çalışan ortak bir yazılım uygulamasıdır [4]. ERP sistemleri işletmeler içerisinde bilgi bütünlüğünün oluşturulduğu ve bilginin dokümante edildiği uygulamalardir.

Rekabet, tüm kurumları hizmet seviyelerini arttırmaya iterken, gelişen teknoloji de ürünlerin yaşam döngülerini kısaltarak ve şirketleri yeni teknolojileri uygulamaya ya da pazar paylarını kaybetme riskine katlanmaya zorlamaktadır. $\mathrm{Bu}$ sürekli değişim ortamında rekabette başarılı olmak, değişen iş şartlarını önceden tahmin edebilmeyi ve bunlara hızlı yanıt verebilmeyi gerektirir. Kurumların bunu yapabilmeleri için işin gerektirdiği tüm alanları güçlü ve aynı zamanda esnek bir biçimde destekleyen bilgi teknolojilerini kullanan, güvenilir bilgi sistemlerine ihtiyacı vardır. Bu sistemler kurumlara, lojistik, proje yönetimi, finans, servis, satış, dağıtım, sevkiyat ve üretime kadar her alanda değişimlere uyum sağlama ve hızlı tepki verme yeteneği kazandıracaktır. Bütün bunları etkin olarak kullanılabilen, ERP sistemleriyle yapmak mümkündür [5]. Ayrıca ERP yazılımları, uluslararası kuruluşlar için kritik önem taşıyan çoklu para birimi ve dil desteği ile birlikte petrol, kimya, bankacılık, sağlık, havacılık gibi kendine özel sektörleri de destekleyebilmektedir [6].

Sistemlerde darboğazı bulmak için öncelikle en yavaş işleyen ya da önünde en çok iş biriken sürece bakmak yeterli olacaktır [7]. Firmalarda istenilen verim artışı bu dar boğazların belirlenmesi ile artış gösterecektir. Verimliliğin genel tanımı; ürün ya da hizmet olarak yaratılan çıktının, girdi verilerine oranıdır. Bu yönüyle verimlilik; işçilik, sermaye, toprak, malzemeler, enerji ve bilgi olarak tanımlanan beş girdi kaynağının etkin kullanımı olarak da tanımlanabilir [8].

Sistemin gücü en zayıf halkanın gücü kadardır. Sistem ancak kısıtının üretebildiği kadar çıktı üretebilir. Üretim hattında sistemin kısıtı darboğaz kaynaklardır. Darboğaz kaynakta meydana gelen süre kayıpları direkt olarak akışı düşürecektir. Üretim sisteminin etkili bir şekilde yönetilmesi için darboğaz kaynaklara odaklanılmalıdır [9]. 
Talaşlı imalat yapan bir firma için ERP yöntemi kullanılarak dar boğaz alanı belirlenmiş ve bu alan üzerinde gerekli incelemeler yapılmıștır. İncelemeler sonrasında bu firmada meydana gelen verimsizliğin esas nedeninin Torna ve freze tezgahlarında çalışan operatörlerin tesis içerisinde fikstür, ölçü aleti, torna ayağı, pens, flanş, vb. gibi yardımcı ekipmanların aranması hususunda ciddi mesai harcamalarından kaynaklandığı belirlenmiş olup dar boğaz olarak bu etmen ele alınmıştır. Ayrıca çalışmada sistemin kurulmadan önceki durumu ve kurulduktan sonraki durumu karșlaștırılmıș, kazanılan süre ortaya çıkarılmış ve kurulan sistemin geliştirilebilirliği tartışılmıştır.

\section{Materyal ve Metot}

Bir sistem içerisinde dar boğazların tespit edilmeden önce sistemin çok iyi analiz edilmesi gereklidir. Aksi takdirde imalatın aksaması ve müşterilere zamanında teslimatlarda gecikmeler yaşanması muhtemeldir. Müșteriye odaklanma denince akla ilk gelen Tam Zamanında Üretim (TZÜ) felsefesidir. Bu sisteminin uygulanma amacı, müşteri ihtiyaçlarını tam olarak karşlayacak sistem kapasitesini veren üretim ritmini dengelemektir. TZÜ çekme bazlı bir sistem olduğundan, müşteri talebi doğrudan üretim ritmini dengeler [10]. Tam zamanında üretim felsefesinin işletmelere yerleştirilebilmesi için imalatın bütün süreçlerinde detaylı analizler yapılmalıdır. Bu analiz bir talaşlı imalat tesisinde şu şekilde olmalıdır. Öncelikle ham parçaların tezgâhlara ne zaman geldiği ve kuyrukta bekleme süresi araştırılmalıdır. Kuyrukta bekleme süresi bir günü aşan parçalar verimsizlik ortaya çıkaracaktır. Daha sonra analiz edilecek kısım ham parçaların tezgâhlara bağlanmaya başlanıp kesme işleminin başlamasına kadar geçen süredir. $\mathrm{Bu}$ süreye setup süresi adı da verilmektedir. Bu süre çok iyi analiz edilmelidir çünkü bu süreç tamamen insana bağlı bir periyottur. İște tam da bu periyot içerisinde giriş kısmında açıklanan dar boğaz tespit edilmiștir. $\mathrm{Bu}$ dar boğaz, operatörün ham malzemeyi bağlamak için iş sayfasında yazılan yardımcı ekipmanların nerede olduğunu aramasıyla başlamakta olup ham malzemenin tezgâha bağlanmasına kadar devam etmektedir. Firma içerisinde kullanılan ERP yazılımı ve bireysel gözlemler neticesinde bu dar boğaz fark edilmiştir.

Çalışmaya başlamadan önce ilk olarak mevcut durum sayısal verilerle modellenmiștir. Bu modelleme çerçevesinde parça gruplarından çeşitlilik sağlanması için rastgele seçim yapılmış ve on farklı parça grubu oluşturulmuştur.

Tablo 1. 2020-2025 yılları arasında satış adedi en yüksek parça grupları

\begin{tabular}{|c|c|}
\hline Parça Grubu & Üretim Adetleri \\
\hline A Grubu & 970 \\
\hline B Grubu & 822 \\
\hline
\end{tabular}

\begin{tabular}{|l|l|}
\hline C Grubu & 710 \\
\hline D Grubu & 677 \\
\hline E Grubu & 640 \\
\hline F Grubu & 585 \\
\hline G Grubu & 580 \\
\hline H Grubu & 543 \\
\hline I Grubu & 473 \\
\hline J Grubu & 466 \\
\hline
\end{tabular}

Seçilen bu parça gruplarındaki zaman kayıpları birer birer kaydedilmiștir. Ayrıca firmanın kullanmış olduğu ERP programı aracılığıyla 2015 ve 2020 yılları arasında bu parça gruplarındaki ortalama setup süreleri hesaplanmıştır. Hesaplanmış olan ortalama setup süreleri Tablo 2 . de gösterilmiştir.

Tablo 2. Geçmiş yıllara ait ortalama setup süreleri

\begin{tabular}{|c|c|}
\hline Parça Grubu & $\begin{array}{c}\text { Ortalama setup süresi } \\
(\mathrm{dk})\end{array}$ \\
\hline A Grubu & 39 \\
\hline B Grubu & 27 \\
\hline C Grubu & 54 \\
\hline D Grubu & 45 \\
\hline E Grubu & 83 \\
\hline F Grubu & 37 \\
\hline G Grubu & 110 \\
\hline H Grubu & 70 \\
\hline I Grubu & 22 \\
\hline J Grubu & 30 \\
\hline
\end{tabular}

Tablo 1 ve tablo 2 'deki veriler göz önüne alındığında on farklı parçasının setup sürelerinde yapılacak en küçük bir iyileştirmenin bile firmaya uzun vadede ciddi kazanımlar sağlayacağı aşikârdır.

Talaşlı imalatta setup işlemleri yapıldıktan sonra operatör parça programını tezgâha çağırır ve tezgâhta imalat başlar. Bu noktadan ham malzemenin kesici takımlar ile işlenmesi bitene kadar geçen süreye ise makine süresi adı verilir. Bu süre program süresi olmakla birlikte kesim metodu, devir ilerleme hızl, spindle hızı gibi etkenlere bağlıdır. Bu sebeple genel anlamda makine süresi operatör kabiliyetlerine bağlı değildir.

Çalışma konusu üzerine tasarlanan yazılım ve ara yüz firma genelinde kullanılmakta olan tabletlere entegre edilecektir. Mevcut durumda firma bünyesinde çalışan operatörler bu tabletler üzerinden bir ERP programı aracılığıyla iş emri açma-kapama işlemleri yapmaktadırlar. Yapılacak olan yazılım ve ara yüz bu tabletlere kurulacak ve operatörler için kullanımı kolaylaştırılacaktır. Mevcut kullanılan tabletler ek 
olarak yalnızca QR kod tarayıcılar entegre edilecektir. Yüksek çözünürlükle uzak mesafeden bile görüntü işleme yeteneğine sahip QR kod tarayıcıların kullanılması kullanım kolaylığı sağlayacağı gibi sistemin sürdürülebilirliğine de katkısı olacaktır. Firma genelindeki iletişim ve ağ altyapısının da yeterli olması büyük yatırım maliyetlerine ihtiyaç bırakmamıştır. Uygulanacak ilk adım C programlama dili ile program genel altyapısının oluşturulması ile parça numaralarına ait QR kodlarının oluşturulması ve hafizaya aktarılmasıdır. Daha sonra mevcut yardımcı aparatların konumları sisteme aktarılacak, QR kodları aracılı̆̆ı ile yardımcı aparatların konumları ilişkilendirilecektir.

Ekipmanlar üzerine QR kodların yerleşiminin son derece titizlikle yapılması önemlidir. Çünkü deformasyon sonucu QR kodların, QR tarayıcilar tarafından okunmaması durumunda bazı aksamalar meydana gelebilir. Kodların fikstür ve yardımcı ekipmanların üzerine yerleșimleri görülebilir alanlarda ve QR tarayıcının okuyabileceği derinlikte olmalıdır.

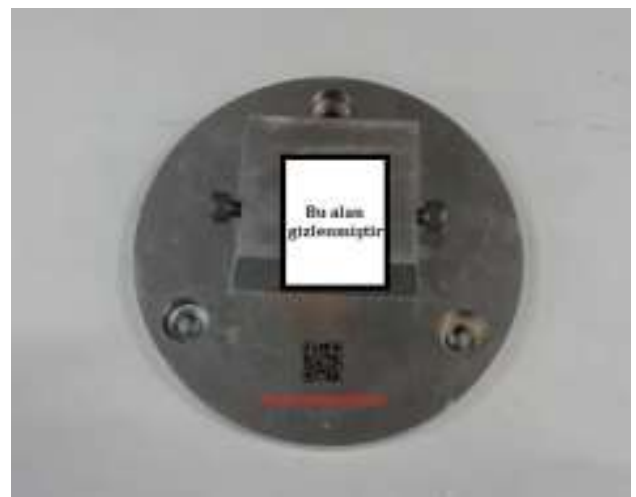

Şekil 1. Fikstür üzerine yerleştirilmiş QR kod [11]

Firma içerisindeki imalat süreci iş emirleri aracılı̆̆ıyla gerçekleşmektedir. Bir parçanın iş emri olmadan hiçbir şekilde talaşlı imalatı yapılamamaktadır. Eğer bir parçanın iş emri olmadan imalatı yapılırsa ana sistem üzerinden o tezgah duruş halinde olarak görülmekte ve sorumluları otomatik sinyal ile uyarmaktadır. Mevcut durumda operatör, iş emirleri üzerinde yazan iş emri numarasını (PO Number) ERP sistemine girerek işi başlatma, durdurma ve bitirme gibi değișiklikleri yapmaktadır.

Makale konusu kapsamında anlatılan sistemin yürütülebilmesi için iș emirlerinin üzerine her bir iş emrine özgü olan QR kodlar yerleştirilmeye başlanılmıștır. Operatör tezgâhlara zimmetli olan tabletler aracilığıyla bu QR kodu okuttuğunda, tablet ekranında iș emri bilgilerinin bulunduğu sayfa açılır. $\mathrm{Bu}$ sayfada yapılacak olan iş emrine ait imalatın başlatılması ve durdurulması işlemleri, imalatı yapılan parça numarası, kaç adet yapılacağı gibi bilgiler ve sekmeler görüntülenir. Makale konusunda araştırılan ve kullanılacak ekipmanlar ise "yardımcı ekipmanlar" sekmesi altında görüntülenir.
Kullanıcı, yardımcı ekipmanlar sekmesine tıkladığı zaman açllan sayfada fikstür, yükselti, pens, flanş, ölçü aleti gibi yardımcı ekipmanların konumuna ulaşabildiği gibi en son kimin kullandığına ya da kullanılmakta olan birime ve/veya kişiye ait bilgileri de görebilecektir. Kullanıcı listede yer alan yardımcı ekipmanlardan birisinin QR kodunu okuttuğu zaman bu yardımcı ekipmanın zimmeti kullanıcı üzerinde görünecek ve ilgili ekipmanın sorumluluğunu alacaktır. $\mathrm{Bu}$ sayede kullanıcılara sorumluluk bilincinin de yerleştirilmesi sağlanacaktır. Nitekim sistemin uygulanmaya başlamasıyla birlikte kullanıcılarda istenilen etki gözlenmiștir.

Bu bağlam ve yöntem ile birlikte makale konusunu da oluşturan iyileștirme çalışması setup sürelerinin azaltılması yönünde yazılımsal bir çalıșma olması amaçlanmıştır.

\section{Bulgular}

Fikstür ve yardımcı ekipmanların takibinin ve kontrolünün yapıldı̆̆ı makale konusu pilot bölgede uygulanmaya başlandıktan sonra yeni veriler edinilmeye başlanılmıştır. Bu yeni veriler örneklem olarak seçilen on farklı parça grubunda toplanmıștır.

Bu örneklem parça gruplarının imalatı üçüncü kişi olarak seyredildi ve operatörlerin setup süreleri gerçek zamanlı olarak da toplanmaya başlanıldı. Ayrıca aynı dönem içerisinde operatörlerin ERP programına girdiği setup süreleri de hesaplandı. Toplanan bu veriler Tablo 3'de gösterilmiştir.

Tablo 3. Geçmiş yıllara ait ortalama setup süreleri ve sapmalar

\begin{tabular}{|c|c|c|c|}
\hline $\begin{array}{c}\text { Parça } \\
\text { Grubu }\end{array}$ & $\begin{array}{c}\text { Ortalama setup } \\
\text { süreleri (dk- } \\
\text { tezgah başındaki } \\
\text { süreler) }\end{array}$ & $\begin{array}{c}\text { Ortalama setup } \\
\text { süreleri (dk-ERP } \\
\text { süreleri) }\end{array}$ & Sapma \\
\hline A Grubu & 30 & 28,2 & $-6,4 \%$ \\
\hline B Grubu & 18 & 18,7 & $3,7 \%$ \\
\hline C Grubu & 40 & 42,1 & $5,0 \%$ \\
\hline D Grubu & 39 & 38,8 & $-0,5 \%$ \\
\hline E Grubu & 70 & 67,2 & $-4,2 \%$ \\
\hline F Grubu & 25 & 24,2 & $-3,3 \%$ \\
\hline G Grubu & 80 & 82,3 & $2,8 \%$ \\
\hline H Grubu & 55 & 52,8 & $-4,2 \%$ \\
\hline I Grubu & 17 & 18,1 & $6,1 \%$ \\
\hline J Grubu & 22 & 23,3 & $5,6 \%$ \\
\hline
\end{tabular}

01.02.2020 tarihinden 01.05.2020 tarihine kadar üçüncü şahısların sahadan topladığı gerçek setup süreleri ile operatörlerin ERP programına girdiği setup süreleri karşılaștırılarak Tablo 2'de gösterilen geçmiş yıllara ait setup süresi verilerinin güvenilirliği sağlanmıştır.

Makale konusu, firma içerisinde pilot bölge olarak tanımlanan alanda 01.02.2020 tarihi itibariyle yürürlüğe girmiştir. Elde edilen verilere göre 10 parça 
için toplamda 121 dakika iyileştirme yapılmıştır. Parça grupları bazında parça başına iyileştirme süreleri ve kümülatif kazanılan süreler Tablo 4 ve Tablo 5'te gösterilmiştir. 2020-2025 yılları arasındaki toplam üretim adetleri ile bu iyileştirme süreleri çarpıldığında önümüzdeki beş yıl içinde toplam 77.108 dakikalık yani 1.285 saatlik tasarruf edilmiş olacaktır. Bu veri sadece 10 parça grubuna ait olan tasarruf süresidir. Seçilen parça gruplarına pilot bölgede uygulanan sistemin öncelikle tesis geneline sonrasında ise firma geneline adapte edilmesi düşünülmektedir.

Tablo 4. Geçmiş yıllara ait ortalama setup süreleri (dakika)

\begin{tabular}{|c|c|c|c|}
\hline $\begin{array}{c}\text { Parça } \\
\text { Grubu }\end{array}$ & $\begin{array}{c}\text { 2015-2020 } \\
\text { yllarına ait } \\
\text { ortalama } \\
\text { setup } \\
\text { süreleri }\end{array}$ & $\begin{array}{c}\text { Güncel } \\
\text { ortalama } \\
\text { setup } \\
\text { süreleri } \\
\text { (Güncel) }\end{array}$ & $\begin{array}{c}\text { İyileşme } \\
\text { Süresi } \\
\text { (birim } \\
\text { adet) }\end{array}$ \\
\hline A Grubu & 30 & 28,2 & 9 \\
\hline B Grubu & 18 & 18,7 & 9 \\
\hline C Grubu & 40 & 42,1 & 14 \\
\hline D Grubu & 39 & 38,8 & 6 \\
\hline E Grubu & 70 & 67,2 & 13 \\
\hline F Grubu & 25 & 24,2 & 12 \\
\hline G Grubu & 80 & 82,3 & 30 \\
\hline H Grubu & 55 & 52,8 & 15 \\
\hline I Grubu & 17 & 18,1 & 5 \\
\hline J Grubu & 22 & 23,3 & 8 \\
\hline
\end{tabular}

Tablo 5. 2020-2025 yılları arasındaki toplam kazanç

\begin{tabular}{|c|c|}
\hline Parça grubu & $\begin{array}{c}\text { Toplam Kazanım } \\
\text { Süresi (dakika) }\end{array}$ \\
\hline A Grubu & 8.730 \\
\hline B Grubu & 7.398 \\
\hline C Grubu & 9.940 \\
\hline D Grubu & 4.062 \\
\hline E Grubu & 8.320 \\
\hline F Grubu & 7.020 \\
\hline G Grubu & 17.400 \\
\hline H Grubu & 8.145 \\
\hline I Grubu & 2.365 \\
\hline J Grubu & 3.728 \\
\hline
\end{tabular}

Parça grupları arasında en fazla iyileştirme gözlemlenen grup G grubu parçalardadır.

Makale konusunun firma geneline adapte olması durumunda elde edilen kazanç verilerinde ciddi kazanımlar olacaktır. Yalnızca pilot bölge genelinde 670 farklı proses yer almaktadır. Araştırılan proses sayısı ise yalnızca 10 farklı prosestir. Sadece pilot bölge genelinde 120 kişi çalışmaktadır. Resmi tatiller düşüldügünde 1 kişi 2020 yılı boyunca 6552 saat çalışacaktır. Dolayısıyla 2020 yılında 120 kişi toplamda 786.240 saat çalışacaktır. Önümüzdeki 5 yıl dikkate alınırsa toplam kapasitemiz 3.931.200 saat olacaktır.

Seçilen 10 parça grubuna ait iyileştirme sürelerinin ortalaması (Örneklem Ortalaması) Tablo 6'da hesaplanmıştır.

Tablo 6. Örneklem Ortalaması (saat)

\begin{tabular}{|c|c|}
\hline $\begin{array}{c}\text { Parça } \\
\text { grubu }\end{array}$ & Kümülatif iyileştirme (saat) \\
\hline A Grubu & 146 \\
\hline B Grubu & 123 \\
\hline C Grubu & 166 \\
\hline D Grubu & 68 \\
\hline E Grubu & 139 \\
\hline F Grubu & 117 \\
\hline G Grubu & 290 \\
\hline H Grubu & 136 \\
\hline I Grubu & 39 \\
\hline J Grubu & 62 \\
\hline Toplam & 1.286 \\
\hline Ortalama & 128,6 \\
\hline
\end{tabular}

Özetlenecek olursa yapılan araştırma belirtildiği gibi 10 farklı proses için gerçekleştirilmiştir. Ancak pilot bölge genelinde toplamda 670 farklı proses yer almaktadır. Toplam kapasiteye ulaşabilmek amacıyla 5 yılda 10 farklı prosesten elde edilen sürenin ortalamasını toplam proses sayısı ve yanılsama katsayısı ile çarpıp yaklaşık tasarruf edilen kapasiteye ulaşılacaktır. Seçilen parça grubundaki ortalama kazanımın 128,6 saat ve pilot bölge genelindeki toplam farklı proses sayısının 670 adet olduğu bilinmektedir. Peki yanılsama katsayısı nedir?

Kâğıt üstündeki bütün verilerin pratikte de aynı sonuç vermesi zor bir ihtimaldir. Yanılsama katsayısı teori ile pratiğin örtüştürüldüğü bir orandır. Hata oranı belirlenmeden yapılan çalışmalarda teorik veriler gerçek ile örtüşmeyecek ve sahada hayal kırıklıkları yaşanacaktır. Yanılsama katsayısı aşağıda belirtildiği gibi uzun süren çalışmalar neticesinde belirlenmiştir. Uygulama yapılan firma genelinde çeşitli ara kontroller ile teorik veriler ve sahadaki gerçek veriler sürekli olarak analiz edilir. Yapılan çalışmada da gerçek ve saha verileri analiz edilerek yanılsama katsayısı (hata oranı) belirlenmiştir. Teorik veriler ERP sistemine işin maliyeti ve karmaşıklığı göz önünde bulundurularak girilen ve referans olan bilgilerdir. Sahadaki veriler ise güncel olarak yapılan işe ait olan anlık verilerdir. Örneğin X parçasının işlemleri ERP sisteminde 100 dakika olarak referans alınmaktadır. $\mathrm{Bu} \mathrm{X}$ parçası güncel olarak sahada 95 
dakika ya da 105 dakika aralı̆̆ında yapılabilir. Ĕger bu aralıkta üretim yapılıyorsa saha verileri ile ERP sistemi uyumlu denilmektedir. Eğer imalat süresi bu aralığın dışında kalıyorsa saha verileri ERP sistemi ile uyumlu değildir. Bu şekilde pilot bölge genelindeki 670 adet farkl prosesin saha verileri birer birer hesaplanarak ERP verileri ile karşılaștırılmış ve 637 adet prosesin saha verilerinin ERP sistemi verileri ile uyumlu olduğu saptanmıştır. Kalan 23 adet prosesin saha verilerinin ise ERP sistemi verileri ile uyumlu olmadığı gözlenmiştir. Bahsi geçen 23 adet proses bizim hata oranımızı oluşturmuştur ve yanılsama katsayısı olarak ifade edilmiştir. $\mathrm{Bu}$ durumda yanılsama katsayımız \%95 olarak hesaplanmıştır.

\section{Toplam kapasite kazancı: TKK}

TKK = Örneklem ortalaması $\mathrm{x}$ Toplam proses adedi $\mathrm{x}$ Yanılsama katsayısı

$\mathrm{TKK}=128,6$ saat $\times 670 \times 0,95=81.853,9$ saat

Yapılan hesaplamalara göre toplam kapasite içerisinden 81.853,9 saat iyileştirilmiştir. Bu iyileştirilen süre toplam kapasitenin \%2,08 ine denk gelmektedir.

Firma içerisinde maliyet hesapları yapılırken tezgâh saat ücreti 60 olarak işlemler yapılmaktadır. Bu fiyat mevcut sektör giderleri doğrultusunda yıllık bazda hesaplanmaktadır. $\mathrm{Bu}$ fiyatlama üzerinden hesap edecek olursak parça gruplarına göre 2020 ve 2025 yılları arasındaki kazanç miktarı şekil 2.'deki gibi olacaktır.

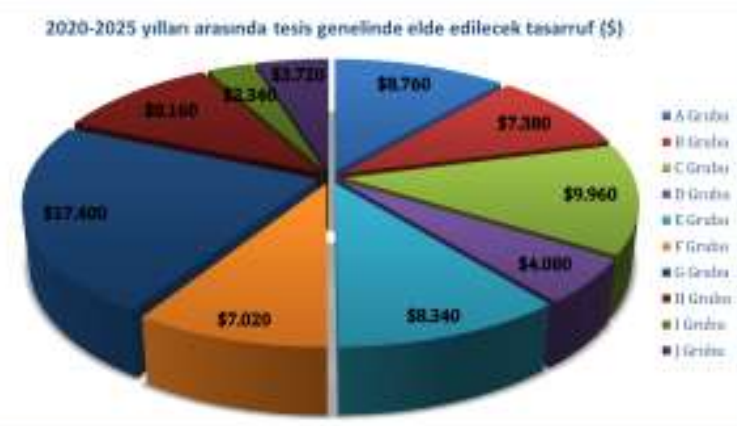

Şekil 2. Çalışmanın 2020-2025 yılları arasında pilot bölgeden tesis geneline yayılması ile elde edilecek toplam tasarruf miktarı [11]

Tüm bu veriler neticesinde talaşlı imalat yapan firmaların proseslerini sürekli iyileştirmeleri elzemdir. Pilot olarak seçilen bölgenin sadece 5 yıl sonunda kapasitesinin \%2,08 artırılması firmaya ciddi kazanımlar sağlayacaktır. $\mathrm{Bu}$ kazanımlar yeni müșteriler ya da siparișler olabileceği gibi personeline eğitimler vererek kalifiye hale getirmesi neticesinde sektördeki rakiplerine fark atması da olabilir. Ayrıca gerçekleştirilmiş çalışma içerisinde kayda değer bir yatırım olmamış; sadece firma içerisindeki potansiyelin harekete geçirilmesi sonucu bu kazanç ortaya çıkmıştır. $\mathrm{Bu}$ potansiyel firmanın kalifiye personeli, güçlü altyapısı ve gelişime açıklığı olarak ifade edilebilir.

\section{Tartışma ve Sonuç}

$\mathrm{Bu}$ çalışmada yazılım tabanlı bir otomasyon sistemi kurulumunun, talaşlı imalat hizmeti veren bir firma üzerindeki etkileri araştırılmış ve bulgular paylaşılmıştır. Öncelikle rastgele örneklem parça grubu seçilmiș ve bu gruptaki parçaların üretim adetlerinin çok yüksek, çok düşük ve ortalama üretim adetli olmasına dikkat edilerek çeşitlilik sağlanması amaçlanmıştır.

Çalışmada pilot bölgedeki örneklem parça grupları üzerinde devreye alınmadan önce setup süreleri gerçek zamanlı olarak ve ERP programı aracılığıyla takip edilmiş ve sapma oranı hesaplanmıștır. Bu oran hesaplanırken 2015-2020 yılı arasında ERP programından alınan veriler ile gerçek veriler karşılaştırılarak ortalama sapma miktarı belirlenmiştir. Elde edilen veriler karşılaştırıldığında sahadaki veriler ile ERP programında referans alınan verilerin birbirine yakın olduğu görülür. Firmada ERP sistemi verileri ve saha verileri karșılaștırmasının sürekli olarak yapılması neticesinde geçmiş yıllara ait yanılsama oranı (sapma oranı) \%5-6 seviyesinde gerçekleşmiştir. Bu durum da bize ERP programından alınan verilerin güvenilirliğini kanıtlar. Yani belirli bir tarih aralığına yönelik ERP programından veri çekildiğinde hesaplanan çıktının gerçek süreye çok yakın olacağı öngörülmüştür. Ortalama sapma miktarının yüksek çıkması ERP programından alınan verilerin güvenilirliğini azaltırken sapma miktarının düşük çıkması ERP programından alınan verileri gerçek veri olarak kabul etmemizi sağlamıştır.

Çalışma sonunda elde edilen veriler toplanmış ve 2020-2025 yılı toplam kapasitesi hesaplanmıştır. Kurulan sistem bu şekilde yürütülmeye devam ederse önümüzdeki beş yıl içerisindeki toplam kapasiteden $\% 2,08$ tasarruf edileceği ispatlanmıştır.

ERP sistemlerinin ve otomatik takip yazllım ve ara yüzlerinin entegre çalıştığı firmalarda projede de görüldüğü gibi ciddi kazanımların elde edilmesi mümkündür. $\mathrm{Bu}$ otomasyon sistemlerinin efektif şekilde kullanılması sonucu çalıșllabilir iş gücünün yönetimi de kolaylaşacaktır. Belirli iş gruplarında yetkinleşmiş kişiler sadece kendi alanları ile ilgili çalışacak ve firmalar içerisinde değer katmayan hareketler olarak nitelendirilen çalışmaların önüne geçilecektir.

İlerleyen zamanlarda yapılmış olan bu otomasyon sisteminin geliștirilip özellikle Uzakdoğu ülkelerinde verimli şekilde kullanılan ve planlanan iş çizelgesine göre yardımcı ekipmanları tezgâha otomatik olarak getiren robotlar kullanılabilir. Bu robotlar yardımcı 
ekipmanları dikey olarak istiflenmiş otomatik depo sistemlerinden tezgâhlara önceden tanımlanmış yollar üzerinden getirirler. Talaşlı imalat ile robotik otomasyonun birleştirildiği bu çalışmalarla sektördeki ihtiyaçlar giderilmeye çalışılmaktadır.

\section{Kaynakça}

[1] Görçün, Ö. F. 2017. Dördüncü Endüstri Devrimi Endüstri 4.0, Beta Basım A.Ş., 76s

[2] Keçek, G. \& Yıldırım, E., 2009. Kurumsal Kaynak Planlaması (ERP) ve İşletme Açısından Önemi, Elektronik Sosyal Bilimler Dergisi, 29, 240-258.

[3] Laudon, K. \& Laudon J., 2002. Information Systems Management: Organization and Technology, 7a Edition. Prentice Hall. Englewood Cliffs, NJ.

[4] Macvitte, L., 2001. Buckle Up: Implementing an ERP Takes Time and Patience, Network Computing, 12, 97s

[5] Bayraktar, E. \& Efe, M., 2006. Kurumsal Kaynak Planlaması (ERP) Ve Yazılım Seçim Süreci, Selçuk Üniversitesi Sosyal Bilimler Enstitüsü Dergisi, Sayı 15, 693s

[6] O'Leary, D., 2000. Enterprise Resource Planning Systems: Systems, Life Cycle, Electronic Commerce and Risk Cambridge University Press, Cambridge, MA., 34s

[7] Sezen, B., 2011. Üretim Yönetiminde Yeni Yaklaşımlar ve Uygulamalar, Efil Yayınevi, 15s

[8] Prokopenko, J., 1987. Productivity Management, Gérer La Productivité, Geneva, 3s

[9] Altun, K. \& Göleç A., 2011. Üretim Kontrol Sistemlerini Kısıtlayıcı Bir Benzetim Çalışması, Erciyes Üniversitesi, Fen Bilimleri Enstitüsü Dergisi, 27, 203s

[10] NOMAK, A. \& DURMUŞOĞLU, M.B., 2010. Bir hücresel üretim ortamında, üretim planlama ve kontrol sistemlerinin benzetim analizi, İTÜDERGISİ/d, 2, 44s

[11] Duman, M., 2020. Fikstür ve Aparatların Yazılım Aracılığıyla Otomasyonu: Eskişehir İlinde Talaşlı İmalat Yapan Bir Firmada Uygulaması, Yüksek Lisans Tezi, Isparta Uygulamalı Bilimler Üniversitesi Fen Bilimleri Enstitüsü, 49s-64s, Isparta 